\title{
Can nutrient profiling help to identify foods which diet variety should be encouraged? Results from the Whitehall II cohort
}

\author{
Gabriel Masset ${ }^{1,2 *}$, Peter Scarborough ${ }^{3}$, Mike Rayner $^{3}$, Gita Mishra ${ }^{4}$ and Eric J. Brunner ${ }^{1}$ \\ ${ }^{1}$ Research Department of Epidemiology and Public Health, University College London, London, UK \\ ${ }^{2}$ UMR Nutrition, Obésité et Risque Thrombotique, Aix-Marseille Université, Inserm 1062, INRA 1260, \\ 27 Boulevard Jean Moulin, 13385 Marseille Cedex 05, France \\ ${ }^{3}$ British Heart Foundation Health Promotion Research Group, Nuffield Department of Population Health, \\ University of Oxford, Oxford, UK \\ ${ }^{4}$ School of Population Health, University of Queensland, Brisbane, QLD, Australia \\ (Submitted 26 March 2014 - Final revision received 19 February 2015 - Accepted 3 March 2015 - First published online 22 April 2015)
}

\begin{abstract}
Higher variety of recommended foods, identified arbitrarily based on dietary guidelines, has been associated with better health status. Nutrient profiling is designed to identify objectively, based on nutrient content, healthier foods whose consumption should be encouraged. The objective was to assess the prospective associations between total food variety (food variety score, FVS) and variety from selected recommended and non-recommended foods (RFV and NRFV, respectively) and risk of chronic disease and mortality. In 1991-3, 7251 participants of the Whitehall II study completed a 127-item FFQ. The FVS was defined as the number of foods consumed more than once a week. (N)RFV(Ofcom) and (N)RFV(SAIN,LIM) were similarly derived selecting healthier (or less healthier) foods as defined by the UK Ofcom and French SAIN,LIM nutrient profile models, respectively. Multi-adjusted Cox regressions were fitted with incident CHD, diabetes, CVD, cancer and all-cause mortality (318, 754, 137, 251 and 524 events, respectively - median follow-up time 17 years). RFV and NRFV scores were mutually adjusted. The FVS (fourth $v$. first quartile) was associated with a 39 and $26 \%$ reduction of prospective CHD and allcause mortality risk, respectively. The RFV(Ofcom) (third $v$. first quartile) was associated with a 27 and $35 \%$ reduction of all-cause mortality and cancer mortality risk, respectively; similar associations were suggested, but not significant for the RFV(SAIN,LIM). No prospective associations were observed with NRFV scores. The results strengthen the rationale to promote total food variety and variety from healthy foods. Nutrient profiling can help in identifying those foods whose consumption should be encouraged.
\end{abstract}

Key words: Food variety: Nutrient profiling: Whitehall II cohort: Proportional hazards regression

Several approaches have been used for the identification of dietary patterns linked to improved health status of individuals ${ }^{(1-4)}$. Indicators of total food variety have been associated with improved nutritional status, particularly in developing countries ${ }^{(5-9)}$, and higher food variety has been associated with reduced diabetes and colorectal cancer prevalence ${ }^{(10-12)}$. In developed countries, it has been suggested that specific variety from healthy or recommended foods is protective against all-cause mortality and chronic disease ${ }^{(3,13-16)}$. An objective identification of such healthier foods whose consumption should be recommended could assist in the development of food-based dietary guidelines that implicitly include dietary variety as a parameter ${ }^{(17-20)}$.

Nutrient profiling is defined by the WHO as the science of classifying or ranking foods according to their nutritional composition for reasons related to preventing disease and promoting health ${ }^{,(21)}$. A nutrient profile model developed for the UK regulator for broadcast media (Ofcom) is being used for regulatory purposes in its original or adapted version in the UK, the Republic of Ireland, and Australia and New Zealand $^{(22-24)}$. The SAIN,LIM nutrient profile model ${ }^{(25,26)}$ is developed for the French food safety agency as an answer to the European Union regulation on food labelling ${ }^{(27)}$. Other governments and commercial companies around the world have or are proposing to use different models ${ }^{(28)}$.

Selecting healthier foods as defined by nutrient profile models would provide a robust basis to assess the impact on health of an increased variety from selected healthier foods, and to compare with the health effect of an increased

Abbreviations: FVS, food variety score; ICD, International Classification of Disease; MAR, mean adequacy ratio; MER, mean excess ratio; NRFV, nonrecommended food variety scores; Ofcom, UK Ofcom nutrient profiling model; RFV, recommended food variety scores; SAIN,LIM, score for the nutritional adequacy of individual foods, score for disqualifying nutrients.

*Corresponding author: G. Masset, email gabriel.masset@gmail.com 
total food variety. The use of longitudinal data would allow assessing prospective associations with chronic disease risk and mortality events, ensuring the temporality of the associations. The aim of the present study was to assess, within the British Whitehall II cohort, the associations between total food variety and variety from selected healthier foods identified using the UK Ofcom and French SAIN,LIM nutrient profile models and prospective risk of coronary events and diabetes, and mortality.

\section{Subjects and methods}

\section{The Whitehall II cohort}

The target population of the Whitehall II study was all civil servants aged 35-55 years working in the London offices of twenty Whitehall departments in 1985-8. A response rate of $73 \%$ led to the recruitment of 10308 participants, invited to the research clinic at 5-year intervals and receiving a postal questionnaire between clinic phases ${ }^{(29)}$. The last completed clinical phase ended in December 2009. The study was conducted according to the guidelines laid down in the Declaration of Helsinki, and all procedures involving human subjects were approved by the University College London Research Ethics Committee. Written informed consent was obtained from all subjects and renewed at each contact.

\section{Dietary assessment and baseline covariates}

Detailed dietary assessments were introduced between 1991 and 1993, the baseline for the present analysis. Dietary intakes were reported in a validated 127 -item $\mathrm{FFQ}^{(30,31)}$. The FFQ was completed by 7935 respondents. For all items in the FFQ, participants were asked to report their frequency of eating a common unit or portion size during the previous year in nine predefined categories ranging from 'never or less than once per month' to ' $6+/ d$ '.

Clinical examinations were conducted by trained staff at the study clinic or at home. As described in full elsewhere ${ }^{(29,32)}$, height, weight, blood pressure and serum lipids were collected following standard procedures. Employment grade within the British Civil Service (six levels) was used as the measure of adult socio-economic position. Ethnicity (white, South Asian, Afro-Caribbean or other), marital status (married, single, widowed or divorced), smoking habit (never, ex-smoker or current), leisure-time physical activity (hours mild, moderate and vigorous activity per week), prevalence of longstanding illness and medication use were self-reported in the general health questionnaire.

BMI was calculated as the ratio between weight $(\mathrm{kg})$ and height squared $\left(\mathrm{m}^{2}\right)$; subjects were classified as overweight/ obese if their BMI was $\geq 25.0 \mathrm{~kg} / \mathrm{m}^{2}$. Hypertension was defined as systolic or diastolic blood pressure $\geq 140$ or $\geq 90 \mathrm{mmHg}$, respectively, or by the use of hypertensive drugs $^{(33)}$. Dyslipidaemia was defined as serum LDL-cholesterol $\geq 4.1 \mathrm{mmol} / 1$, or serum HDL-cholesterol $\leq 0.9 \mathrm{mmol} / 1$ (men) or $\leq 1 \mathrm{mmol} / 1$ (women), or serum TAG $\geq 1.7 \mathrm{mmol} / 1$, or by the use of lipid-lowering drugs ${ }^{(34,35)}$.

\section{Outcomes follow-up}

Mortality data (median follow-up $17 \cdot 7$ years, range $0 \cdot 08-18 \cdot 4$ years), including the cause of death, were available through the National Health Service Central Registry until 31 January 2010. Death certificates were coded using the 9th or 10th revision of the International Classification of Disease (ICD). A total of 915 incident deaths were recorded within the 171267 person-years of follow-up (mean 16.8 (SD 2.67) years per person). Of these, 419 were attributable to cancer (ICD-9 codes 140-209 except 173 and ICD-10 codes C00-C97 except C44), 259 to CVD (ICD-9 codes 390-458 and ICD-10 codes I00-I99) and 143 to CHD (ICD-9 codes 410-414 and ICD-10 codes I20-I25).

Potential cases of non-fatal myocardial infarction up to 30 December 2009 have been ascertained by questionnaire items on chest pain ${ }^{(36)}$, doctors' diagnoses and hospitalisations (NHS Hospital Episode Statistics database), as described in full elsewhere $^{(4)}$. Myocardial infarction was defined as negative when self-reported only. A total of 416 incident fatal CHD and non-fatal myocardial infarction cases were identified in the 140641 person-years of follow-up (mean 14.5 (SD 5.24) years per person).

Incident cases of diabetes up to 30 December 2009 have been identified by self-report of doctor's diagnosis, diabetic medication and $2 \mathrm{~h} 75 \mathrm{~g}$ oral glucose tolerance test in clinical phases, according to the 1999 WHO classification ${ }^{(37)}$, as described previously ${ }^{(4)}$. A total of 927 incident cases of diabetes were identified with a mean follow-up of 13.9 (SD 4.27) years per person (total 114209 person-years).

\section{The UK Ofcom and SAIN, LIM nutrient profile models}

The UK Ofcom nutrient profile model is a two-category model, scoring food and drinks separately, but using the same basic algorithm - a semi-continuous score based on nutrient and ingredient content - as a basis to define products that are 'healthier' and 'less healthy'. The detailed algorithm has been presented elsewhere ${ }^{(38)}$. The Ofcom model incorporates on a single scale the following components per $100 \mathrm{~g}$ of food: saturated fats, Na, total sugar and energy as the negative components; and protein, fibre and fruit, vegetable, and nut content as the positive components.

The SAIN,LIM nutrient profile model was proposed by the French Food Safety Agency ${ }^{(25,26)}$. It is based on two subscores: the SAIN that includes eight positive nutrients (protein, fibre, vitamin $\mathrm{C}, \mathrm{Ca}, \mathrm{Fe}$, and the optional vitamin $\mathrm{D}$, vitamin $\mathrm{E}$ and $\alpha$-linolenic acid) calculated per $418 \mathrm{~kJ}$ ( $100 \mathrm{kcal}$ ) of food; and the LIM that includes three negative nutrients calculated per $100 \mathrm{~g}$ of food (saturated fats, free sugars and $\mathrm{Na}$ ). Thresholds are defined for each of these sub-scores to define four healthiness classes, with foods from the first class being the 'healthiest' since having a SAIN and a LIM, respectively, higher and lower than the related thresholds, and those in the fourth class being the 'least healthy'.

The Ofcom and SAIN,LIM nutrient profile models were applied to all the items of the FFQ, using the respective nutrient content information. The Ofcom and SAIN,LIM models 
identified sixty-one and forty-nine healthy items, and fiftythree and thirty-nine unhealthy items, respectively. Alcoholic drinks were excluded from the analyses.

\section{Food variety scores}

Five variety scores were calculated for each individual. The food variety score (FVS) was simply the number of FFQ items reported to be consumed more than once a week $^{(6)}$. The recommended food variety scores (RFV(Ofcom) and RFV(SAIN,LIM)) were derived similar to the FVS, counting only the foods identified as 'healthier' and 'healthiest' by the Ofcom and SAIN,LIM models, respectively. In addition, to adjust the variety of recommended foods for the variety from less healthy foods, the non-recommended food variety scores (NRFV(Ofcom) and NRFV(SAIN,LIM)) were computed similar to the RFV selecting foods identified as 'less healthy' and 'least healthy' by the Ofcom and SAIN,LIM models, respectively.

\section{Statistical analyses}

Spearman rank correlations were assessed between the five variety scores. Baseline participant characteristics were tested for heterogeneity across quartiles of all variety scores using one-way ANOVA or $\chi^{2}$ tests. Nutrients and food groups intakes were expressed in density, i.e. on a constant energy basis.

To assess the overall nutritional status, the variety scores were tested against the mean adequacy ratio (MAR) and the mean excess ratio (MER), which do not include variety in their algorithm. The MAR was used to assess average nutritional adequacy for nineteen micronutrients $(\mathrm{Ca}, \mathrm{Mg}, \mathrm{P}, \mathrm{Na}$, $\mathrm{K}, \mathrm{Cl}, \mathrm{Fe}, \mathrm{Zn}, \mathrm{Cu}$, I and vitamins $\mathrm{A}, \mathrm{B}_{1}, \mathrm{~B}_{2}, \mathrm{~B}_{3}, \mathrm{~B}_{6}, \mathrm{~B}_{9}, \mathrm{~B}_{12}, \mathrm{C}$ and D); it was calculated as follow ${ }^{(39)}$ :

$$
\text { MAR }=\sum_{1}^{19} \frac{\text { intake }_{i}}{\mathrm{DRV}_{i}} * \frac{100}{19},
$$

where intake $_{i}$ is the daily intake of nutrient $i$ and $\mathrm{DRV}_{i}$ the respective British Dietary Reference Value ${ }^{(40)}$, taking into account the age and sex of each individual. If intake $e_{i}$ $\mathrm{DRV}_{i}>1$, then intake $i / \mathrm{DRV}_{i}=1$

The MER represented a mean percentage of intakes above maximal recommended amounts for saturated fats, $\mathrm{Na}$ and free sugars and was calculated as follows ${ }^{(41)}$ :

$$
\text { MER }=\left(\sum_{1}^{3} \frac{\text { intake }_{j}}{\mathrm{MRV}_{j}} * \frac{100}{3}\right)-100
$$

where intake is $_{j}$ the daily intake of either saturated fats, $\mathrm{Na}$ or free sugars, and $\mathrm{MRV}_{j}$ the respective maximum recommended value $\left(22 \mathrm{~g}, 3153 \mathrm{mg}\right.$ and $50 \mathrm{~g}$, respectively). If intake ${ }_{j} /$ $\mathrm{MRV}_{j}<1$, then intake ${ }_{j} / \mathrm{MRV}_{j}=1$

Cox proportional hazard regressions ${ }^{(42)}$ were fitted between quartiles of the variety scores and prospective outcomes, using follow-up time in years as time variable. Prevalent cases at baseline were excluded from the analyses. The FVS was assessed individually. To assess independently the effect of healthier and less healthy food variety, the RFV and NRFV scores linked to the same nutrient profile model were mutually adjusted following the approach of Kaluza et al. ${ }^{(16)}$ and Michels et al. ${ }^{(14)}$ Base models were adjusted for age, sex, ethnicity and total energy intake. Further adjustment included marital status, employment grade, smoking status, physical activity level, alcohol intake, BMI categories and prevalence of longstanding illness. Proportional hazard assumption was tested using scaled Schoenfeld residuals ${ }^{(43)}$. Linear trend was assessed by including quartiles of variety scores as continuous variables. All analyses were conducted on a complete case dataset $(n$ 7251) to allow comparison between different levels of adjustment, using the SAS version 9.3 software (SAS Institute, Inc.).

In order to take some account of reporting bias and reverse causality, Cox regressions were conducted excluding either low- and high-energy reporters identified using Goldberg cut-off values ${ }^{(44)}$, or individuals that declared a prevalent longstanding illness or the use of anti-hypertensive or lipidlowering medication at baseline.

The Ofcom score includes fruit, vegetable and nut content as a positive component in its algorithm. Multi-adjusted Cox regressions further including fruit, vegetable, and nut intake as covariate were conducted to assess the contribution of fruit and vegetable intake on the overall results.

\section{Results}

Total food variety was positively correlated with variety of both healthier and less healthy foods (Table 1). RFV and NRFV scores derived from the same nutrient profile model were moderately correlated; correlations were highest between the two RFV scores and the two NRFV scores. Since the main objective of the present study was to compare the effects between increased total variety and increased variety from selected healthier foods, results for the NRFV score are presented in online Supplementary Tables S1-S7.

\section{Baseline characteristics}

For all variety scores, a positive association was observed with high employment grade, and inverse associations with current smoking, physical inactivity and being single (Table 2 and online Supplementary Table S1). Men were more likely to have a higher FVS and NRFV scores, but lower RFV scores; age was positively associated with the RFV scores, and negatively with the NRFV scores. The FVS and RFV (Ofcom) scores were positively associated with prevalent overweight or obesity (i.e. BMI $\geq 25 \mathrm{~kg} / \mathrm{m}^{2}$ ). Higher prevalence of longstanding illness was associated with higher RFV scores.

The five variety scores were associated with increased energy intake, the trend being strongest for the NRFV scores and the FVS (Table 3 and online Supplementary Table S2). The FVS was positively associated with the intake - in g/MJ - of salted snacks and sweets, fish and shellfish, fruit and nuts, and vegetables. The FVS was inversely associated with the intake of dairy products and breads; no association was observed for other food groups. The two RFV scores were positively associated with the consumption of breakfast 
Table 1. Descriptive statistics and Spearman's correlations between the five variety scores $(n 7251)$

\begin{tabular}{|c|c|c|c|c|c|}
\hline & FVS & RFV(Ofcom) & NRFV(Ofcom) & RFV(SAIN,LIM) & NRFV(SAIN,LIM) \\
\hline Mean & $43 \cdot 1$ & $25 \cdot 6$ & $14 \cdot 7$ & $17 \cdot 6$ & $10 \cdot 9$ \\
\hline SD & 11.5 & 7.40 & $5 \cdot 50$ & 6.00 & 4.70 \\
\hline Median & 43 & 25 & 14 & 18 & 11 \\
\hline Range & $0-99$ & $0-51$ & $0-42$ & $0-38$ & $0-32$ \\
\hline \multicolumn{6}{|c|}{ Spearman correlations } \\
\hline FVS & 1 & & & & \\
\hline RFV(Ofcom) & 0.86 & 1 & & & \\
\hline NRFV(Ofcom) & 0.72 & 0.32 & 1 & & \\
\hline RFV(SAIN,LIM) & 0.78 & 0.95 & 0.25 & 1 & \\
\hline NRFV(SAIN,LIM) & 0.69 & 0.33 & 0.91 & 0.23 & 1 \\
\hline
\end{tabular}

cereals and other starches, fish and shellfish, fruit and nuts, and vegetables, and inversely with the intake of breads, and salted snacks and sweets (Table 3). Consumption of dairy products was not associated with the RFV scores. The two NRFV scores were inversely associated with the intake of all food groups except salted snacks and sweets (online Supplementary Table S2).

The FVS and RFV scores were positively associated with overall nutritional adequacy of the diet as indicated by the MAR (Table 3). The FVS and the NRFV scores were positively associated with the MER. The RFV (Ofcom) was weakly, but positively, associated with the MER; there was no association with the RFV(SAIN,LIM). All scores were inversely associated with energy misreporting (both low and high energy reporting). Most associations between the variety scores and macroand micronutrients intake followed the trends highlighted by the MAR and MER (online Supplementary Table S3).

\section{Survival analyses}

The FVS was linearly associated with prospective risk reduction of fatal and non-fatal $\mathrm{CHD}$ and all-cause mortality in the base models (Table 4). Further adjustment attenuated the linear trend estimates, which indicated a borderline significant risk reduction of 11 and $8 \%$ for CHD and allcause mortality, respectively; the hazard ratio estimates for the fourth quartile ( $v$. first) of FVS indicated risk reductions of 39 and $26 \%$ for CHD and all-cause mortality, respectively. A protective association was also suggested for cancer mortality, but estimates were not significant.

A protective effect of the $\mathrm{RFV}$ (Ofcom) on prospective all-cause and cancer mortality was observed in the base and fully adjusted models, significant estimates indicating an approximate $30 \%$ risk reduction for the second and third quartiles ( $v$. first; Table 4). Similar protective effects were suggested for the RFV(SAIN,LIM) second, third and fourth quartiles ( $v$. first), but were not robust to multi-adjustment. For both RFV scores, there was no association with CHD risk. Overall, a higher variety of unhealthy foods, as measured by the NRFV scores, was not associated with prospective risk of $\mathrm{CHD}$, and cancer and all-cause mortality (online Supplementary Table S4).
Similar trends were observed for CVD mortality risk, although the small number of cases led to wider CI and non-significant results (online Supplementary Table S5). No robust association could be observed between the variety scores and diabetes risk (online Supplementary Table S5). Prospective associations were investigated with diet-related cancer mortality (seventy-five cases), but no associations could be observed (data not shown).

\section{Post hoc analyses: diet misreporting and reverse causation}

The exclusion of low and high energy reporters ( $n 1387$ and 545 , respectively) attenuated most associations observed between the variety scores and the risk of CHD (models M2rep in online Supplementary Table S6); the risk reductions obtained with the full sample with the FVS remained suggested, but estimates were non-significant. The protective effect of the FVS on cancer mortality risk was reinforced but with wider CI. The cancer and all-cause mortality risk reductions previously observed with the $\mathrm{RFV}(\mathrm{Ofcom})$ were confirmed.

Excluding individuals who reported a prevalent illness ( $n$ 2427; models M2-ill in online Supplementary Table S6) confirmed the protective effect of the FVS on both CHD and all-cause mortality risk. The protective association between the RFV scores and all-cause mortality were equally confirmed. No significant estimates were observed for the NRFV scores. Excluding individuals who reported the use of antihypertensive or lipid-lowering drug, and those for whom follow-up time was less than 2 years, led to similar conclusions (data not shown).

Further adjusting the Cox regression for fruit, vegetable and nut intake did not modify the overall conclusions (online Supplementary Table S7). Associations with cancer mortality were slightly attenuated; the protective effect of total variety on fatal and non-fatal CHD was confirmed.

\section{Discussion}

The present study assessed the prospective associations between both total food variety and variety from recommended - or healthier - foods (FVS and RFV scores, 
respectively) and adverse health outcomes over a long follow-up period. In contrast to previous investigations ${ }^{(14,16)}$, the recommended foods included in the RFV scores were based on validated nutrient profile models. In multiadjusted survival analyses, total food variety was protective against the risk of fatal and non-fatal CHD, and all-cause mortality. Similar associations were suggested for cancer and CVD mortality risk, but estimates were not significant.
Middle quartiles ( $v$. first) of the RFV(Ofcom) were associated with cancer and all-cause mortality risk reduction. Similar risk reductions were suggested for the RFV(SAIN,LIM), but were not robust to adjustment. Higher variety of nonrecommended foods (NRFV scores) was not associated with prospective health status. Post boc analyses did not alter conclusions, including when adjusting for fruit, vegetable and nut intake.

Table 2. Baseline sociodemographic and risk factor characteristics across variety score quartiles

(Mean values with their standard errors; number of subjects and percentages, $n 7251$ )

\begin{tabular}{|c|c|c|c|c|c|c|c|c|c|}
\hline \multirow{2}{*}{ Score quartiles... } & \multicolumn{2}{|c|}{1} & \multicolumn{2}{|c|}{2} & \multicolumn{2}{|c|}{3} & \multicolumn{2}{|c|}{4} & \multirow[b]{2}{*}{$P^{*}$} \\
\hline & $\%$ or Mear & $n$ or SE & $\%$ or Mean & $n$ or SE & $\%$ or Mear & $n$ or SE & $\%$ or Mean & $n$ or SE & \\
\hline FVS & & 1640 & & 1969 & & 1650 & & 1992 & \\
\hline Range & \multicolumn{2}{|c|}{$0-34$} & \multicolumn{2}{|c|}{$35-42$} & \multicolumn{2}{|c|}{$43-49$} & \multicolumn{2}{|c|}{$50-99$} & \\
\hline Sex (\% men) & $64 \cdot 8$ & 1063 & $68 \cdot 6$ & 1350 & $71 \cdot 0$ & 1172 & $72 \cdot 5$ & 1444 & $<0.001$ \\
\hline Age & & & & & & & & & 0.412 \\
\hline Mean & \multicolumn{2}{|c|}{$49 \cdot 7$} & \multicolumn{2}{|c|}{$49 \cdot 7$} & \multicolumn{2}{|c|}{49.5} & \multicolumn{2}{|c|}{$49 \cdot 4$} & \\
\hline SE & \multicolumn{2}{|c|}{0.15} & \multicolumn{2}{|c|}{0.14} & \multicolumn{2}{|c|}{0.15} & \multicolumn{2}{|c|}{0.14} & \\
\hline Ethnicity (\% white) & $84 \cdot 1$ & 1380 & $92 \cdot 3$ & 1818 & $93 \cdot 8$ & 1548 & $94 \cdot 2$ & 1876 & $<0.001$ \\
\hline Grade (\% high) & $10 \cdot 2$ & 168 & $15 \cdot 6$ & 307 & $19 \cdot 8$ & 326 & 23.7 & 473 & $<0.001$ \\
\hline$\%$ Single & $21 \cdot 6$ & 354 & 14.4 & 283 & 11.2 & 185 & 11.3 & 225 & $<0.001$ \\
\hline$\%$ Current smoker & $18 \cdot 4$ & 301 & $14 \cdot 8$ & 291 & $11 \cdot 0$ & 181 & $10 \cdot 6$ & 211 & $<0.001$ \\
\hline$\%$ Inactive & $73 \cdot 6$ & 1207 & $67 \cdot 8$ & 1335 & $64 \cdot 1$ & 1058 & $59 \cdot 7$ & 1190 & $<0.001$ \\
\hline BMI $\left(\mathrm{kg} / \mathrm{m}^{2}\right)$ & $25 \cdot 2$ & $0 \cdot 10$ & $25 \cdot 1$ & 0.08 & $25 \cdot 1$ & 0.09 & $25 \cdot 4$ & 0.08 & 0.075 \\
\hline$\%$ Overweight/obese & $44 \cdot 8$ & 735 & 45.5 & 896 & $46 \cdot 5$ & 767 & $49 \cdot 4$ & 984 & 0.025 \\
\hline \% Hypertension & $20 \cdot 1$ & 330 & $19 \cdot 7$ & 387 & $20 \cdot 8$ & 343 & $20 \cdot 8$ & 414 & 0.786 \\
\hline \% Dyslipidaemia & $66 \cdot 8$ & 1096 & 68.0 & 1339 & $65 \cdot 2$ & 1076 & $67 \cdot 7$ & 1348 & 0.294 \\
\hline$\%$ Longstanding illness & $32 \cdot 2$ & 528 & 33.5 & 659 & 33.9 & 560 & $34 \cdot 1$ & 680 & 0.624 \\
\hline RFV(Ofcom) & \multirow{2}{*}{\multicolumn{2}{|c|}{$0-19$}} & & 1749 & & 2148 & & 1826 & \\
\hline Range & & & & & & & 31 & & \\
\hline Sex (\% men) & $75 \cdot 5$ & 1153 & $70 \cdot 7$ & 1237 & $68 \cdot 2$ & 1465 & $64 \cdot 3$ & 1174 & $<0.001$ \\
\hline Age & & & & & & & & & 0.009 \\
\hline Mean & & & & & & & $4 \varsigma$ & & \\
\hline $\mathrm{SE}$ & & & & & & & 0 & & \\
\hline Ethnicity (\% white) & 89.0 & 1360 & $91 \cdot 1$ & 1594 & 93.4 & 2006 & 91.0 & 1662 & $<0.001$ \\
\hline Grade (\% high) & 11.5 & 176 & $15 \cdot 9$ & 278 & $19 \cdot 3$ & 415 & $22 \cdot 2$ & 405 & $<0.001$ \\
\hline$\%$ Single & $22 \cdot 3$ & 340 & $15 \cdot 0$ & 263 & $12 \cdot 0$ & 258 & $10 \cdot 2$ & 186 & $<0.001$ \\
\hline$\%$ Current smoker & $19 \cdot 3$ & 295 & $14 \cdot 4$ & 251 & 11.9 & 256 & 9.97 & 182 & $<0.001$ \\
\hline$\%$ Inactive & $71 \cdot 7$ & 1096 & 69.0 & 1207 & 64.4 & 1384 & $60 \cdot 4$ & 1103 & $<0.001$ \\
\hline BMI $\left(\mathrm{kg} / \mathrm{m}^{2}\right)$ & $25 \cdot 1$ & $0 \cdot 10$ & $25 \cdot 1$ & 0.09 & $25 \cdot 2$ & 0.08 & $25 \cdot 5$ & 0.09 & 0.004 \\
\hline$\%$ Overweight/obese & $44 \cdot 2$ & 675 & $46 \cdot 5$ & 814 & $46 \cdot 2$ & 992 & $49 \cdot 3$ & 901 & 0.026 \\
\hline \% Hypertension & $19 \cdot 4$ & 296 & $19 \cdot 8$ & 347 & $20 \cdot 6$ & 442 & $21 \cdot 3$ & 389 & 0.517 \\
\hline \% Dyslipidaemia & $67 \cdot 7$ & 1035 & $68 \cdot 8$ & 1203 & $65 \cdot 7$ & 1412 & $66 \cdot 2$ & 1209 & 0.175 \\
\hline$\%$ Longstanding illness & $30 \cdot 8$ & 470 & 33.7 & 589 & $33 \cdot 0$ & 708 & $36 \cdot 1$ & 660 & 0.011 \\
\hline RFV(SAIN,LIM) & & 1508 & & 2091 & & 1764 & & 1888 & \\
\hline Range & & & & & & & 22 & & \\
\hline Sex (\% men) & $77 \cdot 7$ & 1172 & $71 \cdot 3$ & 1490 & $68 \cdot 7$ & 1211 & $61 \cdot 2$ & 1156 & $<0.001$ \\
\hline Age & & & & & & & & & $<0.001$ \\
\hline Mean & & & & & & & & & \\
\hline $\mathrm{SE}$ & & & & & & & & & \\
\hline Ethnicity (\% white) & $91 \cdot 1$ & 1374 & $91 \cdot 1$ & 1904 & 92.9 & 1638 & $90 \cdot 4$ & 1706 & 0.052 \\
\hline Grade (\% high) & $12 \cdot 1$ & 183 & $16 \cdot 1$ & 337 & $18 \cdot 8$ & 331 & $22 \cdot 4$ & 423 & $<0.001$ \\
\hline$\%$ Single & $21 \cdot 6$ & 326 & $14 \cdot 2$ & 297 & $12 \cdot 4$ & 218 & $10 \cdot 9$ & 206 & $<0.001$ \\
\hline$\%$ Current smoker & $19 \cdot 5$ & 294 & $13 \cdot 4$ & 281 & $12 \cdot 1$ & 214 & $10 \cdot 3$ & 195 & $<0.001$ \\
\hline$\%$ Inactive & 71.4 & 1077 & $69 \cdot 4$ & 1452 & $64 \cdot 4$ & 1136 & $59 \cdot 6$ & 1125 & $<0.001$ \\
\hline BMI $\left(\mathrm{kg} / \mathrm{m}^{2}\right)$ & $25 \cdot 2$ & $0 \cdot 10$ & $25 \cdot 1$ & 0.08 & $25 \cdot 1$ & 0.08 & $25 \cdot 4$ & 0.09 & 0.083 \\
\hline$\%$ Overweight/obese & $45 \cdot 3$ & 683 & $46 \cdot 8$ & 978 & $45 \cdot 6$ & 804 & 48.6 & 917 & 0.192 \\
\hline \% Hypertension & $19 \cdot 0$ & 287 & $19 \cdot 7$ & 412 & 21.0 & 370 & 21.5 & 405 & 0.262 \\
\hline \% Dyslipidaemia & 68.4 & 1031 & 68.5 & 1432 & $65 \cdot 0$ & 1147 & $66 \cdot 2$ & 1249 & 0.069 \\
\hline \% Longstanding illness & $31 \cdot 7$ & 478 & 31.9 & 668 & $34 \cdot 1$ & 602 & $36 \cdot 0$ & 679 & 0.019 \\
\hline
\end{tabular}

FVS, food variety score (total food variety); RFV, recommended food variety score (healthier food variety); Ofcom, UK Ofcom nutrient profiling model ${ }^{(38)}$; SAIN,LIM, score for the nutritional adequacy of individual foods, score for disqualifying nutrients ${ }^{(26)}$

* Test for heterogeneity across quartiles, based on ANOVA for continuous variables, $\chi^{2}$ test for categorical variables. 
Consistent with previous observations ${ }^{(5-9,13,14,16)}$, Whitehall II participants with higher FVS and RFV scores had a higher nutritional adequacy and a higher energy intake. They were also more likely to have a higher employment grade and to be more active, and less likely to be current smokers. These results strengthen previous evidence that diet variety, especially from recommended foods, is associated with healthier behaviours $^{(13,14,16)}$ and further explain the protective effect of dietary variety on prospective mortality and CHD risk. However, participants with higher FVS and RFV scores were more likely to be

Table 3. Baseline dietary characteristics across variety score quartiles

(Mean values with their standard errors)

\begin{tabular}{|c|c|c|c|c|c|c|c|c|c|}
\hline \multirow{2}{*}{ Score quartiles... } & \multicolumn{2}{|c|}{1} & \multicolumn{2}{|c|}{2} & \multicolumn{2}{|c|}{3} & \multicolumn{2}{|c|}{4} & \multirow[b]{2}{*}{$P^{*}$} \\
\hline & Mean & SE & Mean & SE & Mean & SE & Mean & SE & \\
\hline \multicolumn{10}{|l|}{ FVS } \\
\hline Energy (MJ) & 7.41 & 0.06 & $8 \cdot 85$ & 0.05 & 9.67 & 0.06 & 11.5 & 0.07 & $<0.001$ \\
\hline \multicolumn{10}{|l|}{ Food groups ( $\mathrm{g} / 8.4 \mathrm{MJ})$} \\
\hline Meat products and eggs & 127 & 1.95 & 126 & 1.39 & 125 & 1.44 & 126 & $1 \cdot 20$ & 0.853 \\
\hline Fish and shellfish & $32 \cdot 0$ & 0.84 & $32 \cdot 3$ & 0.61 & $32 \cdot 2$ & 0.57 & $34 \cdot 6$ & 0.51 & 0.007 \\
\hline Breads & $94 \cdot 1$ & 1.59 & $90 \cdot 3$ & 1.25 & $86 \cdot 7$ & 1.27 & 78.7 & 1.03 & $<0.001$ \\
\hline Breakfast cereals & 35.8 & 1.22 & $37 \cdot 1$ & 0.90 & 38.5 & 0.95 & $36 \cdot 3$ & 0.74 & 0.224 \\
\hline Other starches & 173 & $2 \cdot 18$ & 177 & 1.64 & 173 & 1.61 & 174 & 1.43 & 0.373 \\
\hline Dairy products & 501 & $11 \cdot 1$ & 455 & 8.78 & 431 & 8.55 & 416 & $7 \cdot 39$ & $<0.001$ \\
\hline Salted snacks and sweets & $73 \cdot 1$ & 1.29 & 79.4 & $1 \cdot 13$ & $79 \cdot 3$ & $1 \cdot 11$ & 88.9 & 1.00 & $<0.001$ \\
\hline Fruit and nuts & 236 & $6 \cdot 01$ & 232 & 4.45 & 257 & 4.92 & 257 & 3.64 & $<0.001$ \\
\hline Vegetables & 215 & 3.68 & 230 & 2.92 & 244 & 3.08 & 248 & $2 \cdot 38$ & $<0.001$ \\
\hline MAR & $92 \cdot 4$ & 0.23 & 97.8 & 0.08 & 99 & 0.05 & 99.7 & 0.02 & $<0.001$ \\
\hline MER & $22 \cdot 7$ & 0.74 & $32 \cdot 7$ & 0.73 & $38 \cdot 9$ & 0.83 & 58.7 & 0.98 & $<0.001$ \\
\hline Acceptable reporters $\dagger$ & \multirow{2}{*}{\multicolumn{4}{|c|}{1478}} & \multirow{2}{*}{\multicolumn{2}{|c|}{1371}} & \multirow{2}{*}{\multicolumn{2}{|c|}{1582}} & $<0.001$ \\
\hline$n$ & & & & & & & & & \\
\hline$\%$ & \multicolumn{2}{|c|}{$54 \cdot 1$} & \multicolumn{2}{|c|}{$75 \cdot 1$} & \multicolumn{2}{|c|}{$83 \cdot 1$} & \multicolumn{2}{|c|}{79.4} & \\
\hline \multicolumn{10}{|l|}{ RFV(Ofcom) } \\
\hline Energy (MJ) & 7.99 & 0.06 & 9.04 & 0.06 & 9.62 & 0.06 & $10 \cdot 8$ & 0.07 & $<0.001$ \\
\hline \multicolumn{10}{|l|}{ Food groups (g/8.4 MJ) } \\
\hline Meat products and eggs & 128 & 1.91 & 126 & 1.48 & 126 & 1.30 & 124 & 1.34 & 0.388 \\
\hline Fish and shellfish & $27 \cdot 3$ & 0.70 & $30 \cdot 1$ & 0.61 & 33.9 & 0.58 & 38.9 & 0.62 & $<0.001$ \\
\hline Breads & $92 \cdot 7$ & 1.59 & $89 \cdot 8$ & 1.33 & $87 \cdot 8$ & $1 \cdot 13$ & 79.2 & 1.14 & $<0.001$ \\
\hline Breakfast cereals & $33 \cdot 4$ & $1 \cdot 14$ & 37.6 & 0.99 & 37.5 & 0.82 & 38.5 & 0.88 & 0.001 \\
\hline Other starches & 166 & $2 \cdot 06$ & 172 & 1.74 & 175 & 1.54 & 183 & 1.54 & $<0.001$ \\
\hline Dairy products & 454 & $10 \cdot 2$ & 445 & $9 \cdot 12$ & 449 & $8 \cdot 27$ & 450 & 8.59 & 0.917 \\
\hline Salted snacks and sweets & 88.2 & 1.41 & $82 \cdot 8$ & $1 \cdot 15$ & 78.4 & 0.99 & 74.5 & 1.03 & $<0.001$ \\
\hline Fruit and nuts & 177 & 4.89 & 213 & 4.47 & 260 & $4 \cdot 17$ & 317 & 4.82 & $<0.001$ \\
\hline Vegetables & 174 & 2.95 & 215 & $2 \cdot 77$ & 246 & 2.66 & 291 & 3.00 & $<0.001$ \\
\hline MAR & 93.1 & 0.24 & $97 \cdot 3$ & 0.11 & 98.8 & 0.06 & 99.5 & 0.04 & $<0.001$ \\
\hline MER & $32 \cdot 2$ & 0.89 & 37.9 & 0.92 & 39.0 & 0.78 & 45.7 & 0.97 & 0.006 \\
\hline Acceptable reporters $\dagger$ & \multirow{2}{*}{\multicolumn{4}{|c|}{1291}} & & & & & $<0.001$ \\
\hline$n$ & & & & & & & & & \\
\hline$\%$ & & & & & & & & & \\
\hline RFV(SAIN,LIM) & & & & & & & & & \\
\hline Energy (MJ) & $8 \cdot 18$ & 0.07 & 9.09 & 0.06 & $9 \cdot 71$ & 0.06 & $10 \cdot 6$ & 0.07 & $<0.001$ \\
\hline Food groups (g/8.4 MJ) & & & & & & & & & \\
\hline Meat products and eggs & 125 & 1.84 & 127 & 1.39 & 127 & 1.42 & 125 & 1.36 & 0.758 \\
\hline Fish and shellfish & $27 \cdot 0$ & 0.64 & 30.5 & 0.57 & 34.0 & 0.62 & 39.1 & 0.66 & $<0.001$ \\
\hline Breads & 93.4 & 1.59 & $90 \cdot 2$ & 1.21 & $85 \cdot 8$ & 1.24 & $80 \cdot 0$ & 1.14 & $<0.001$ \\
\hline Breakfast cereals & $32 \cdot 6$ & 1.09 & $36 \cdot 6$ & 0.87 & 37.4 & 0.97 & $40 \cdot 1$ & 0.89 & $<0.001$ \\
\hline Other starches & 170 & 2.04 & 174 & 1.61 & 174 & 1.66 & 179 & 1.57 & 0.004 \\
\hline Dairy products & 450 & $10 \cdot 2$ & 446 & 8.43 & 442 & 8.94 & 459 & 8.55 & 0.579 \\
\hline Salted snacks and sweets & $90 \cdot 6$ & 1.42 & $82 \cdot 3$ & 1.06 & 78.2 & 1.05 & $72 \cdot 8$ & 1.03 & $<0.001$ \\
\hline Fruit and nuts & 166 & 4.72 & 216 & 3.91 & 260 & 4.64 & 328 & 4.87 & $<0.001$ \\
\hline Vegetables & 163 & 2.65 & 217 & $2 \cdot 50$ & 246 & $2 \cdot 82$ & 301 & 3.07 & $<0.001$ \\
\hline MAR & 93.3 & 0.24 & $97 \cdot 4$ & $0 \cdot 10$ & $98 \cdot 8$ & 0.06 & 99.4 & 0.04 & $<0.001$ \\
\hline MER & 34.2 & 0.94 & $37 \cdot 4$ & 0.83 & 39.7 & 0.84 & 43.8 & 0.96 & 0.555 \\
\hline Acceptable reporters $\dagger$ & & & & & & & & & $<0.001$ \\
\hline$n$ & & & & & & & & & \\
\hline$\%$ & & & & & & & & & \\
\hline
\end{tabular}

FVS, food variety score (total food variety); MAR, mean adequacy ratio ${ }^{(39)}$; MER, mean excess ratio ${ }^{(41)}$; RFV, recommended food variety score (healthier food variety); Ofcom, UK Ofcom nutrient profiling model ${ }^{(38)}$; SAIN,LIM, score for the nutritional adequacy of individual foods, score for disqualifying nutrients ${ }^{(26)}$.

* Test for heterogeneity across quartiles, based on ANOVA for continuous variables, $\chi^{2}$ test for categorical variables.

† Acceptable energy reporters identified using Goldberg cut-off values ${ }^{(44)}$. 
Table 4. Hazard ratio (HR) estimates across variety score quartiles for the risk of fatal and non-fatal CHD, all-cause mortality and cancer mortality (Hazard ratios and $95 \%$ confidence intervals)

\begin{tabular}{|c|c|c|c|c|c|c|c|c|c|c|c|c|}
\hline \multirow[b]{3}{*}{ Score quartiles/trend } & \multicolumn{4}{|c|}{$\begin{array}{l}\text { Fatal and non-fatal CHD } \\
\quad(n 318 \text { cases/7174) }\end{array}$} & \multicolumn{4}{|c|}{$\begin{array}{l}\text { All-cause mortality } \\
\quad(n 524 / 7242)\end{array}$} & \multicolumn{4}{|c|}{$\begin{array}{l}\text { Cancer mortality } \\
\text { (n 251/7235) }\end{array}$} \\
\hline & \multicolumn{2}{|c|}{ Model $1^{*}$} & \multicolumn{2}{|c|}{ Model 2} & \multicolumn{2}{|c|}{ Model 1} & \multicolumn{2}{|c|}{ Model 2} & \multicolumn{2}{|c|}{ Model 1} & \multicolumn{2}{|c|}{ Model 2} \\
\hline & HR & $95 \% \mathrm{Cl}$ & HR & $95 \% \mathrm{Cl}$ & HR & $95 \% \mathrm{Cl}$ & $\mathrm{HR}$ & $95 \% \mathrm{Cl}$ & $\mathrm{HR}$ & $95 \% \mathrm{Cl}$ & $\mathrm{HR}$ & $95 \% \mathrm{Cl}$ \\
\hline \multicolumn{13}{|l|}{ FVS } \\
\hline 1 & Ref & & Ref & & Ref & & Ref & & Ref & & Ref & \\
\hline 2 & 0.70 & $0.52,0.96$ & 0.74 & $0.54,1.01$ & 0.75 & $0.59,0.95$ & 0.80 & $0.63,1.02$ & 0.75 & $0.54,1.06$ & 0.75 & $0.53,1.06$ \\
\hline 3 & 0.84 & $0.61,1.16$ & 0.90 & $0.65,1.25$ & 0.75 & $0.58,0.97$ & 0.82 & $0.63,1.06$ & 0.68 & $0.47,1.00$ & 0.68 & $0.46,1.00$ \\
\hline 4 & 0.56 & $0.39,0.81$ & 0.61 & $0.42,0.89$ & 0.67 & $0.50,0.88$ & 0.74 & $0.56,0.99$ & 0.75 & $0.50,1.11$ & 0.73 & $0.49,1.10$ \\
\hline Trend† & 0.86 & $0.77,0.97$ & 0.89 & $0.79,1.00$ & 0.89 & $0.81,0.97$ & 0.92 & $0.84,1.01$ & 0.91 & $0.79,1.03$ & 0.90 & $0.79,1.03$ \\
\hline \multicolumn{13}{|l|}{ RFV(Ofcom) } \\
\hline 1 & Ref & & Ref & & Ref & & Ref & & Ref & & Ref & \\
\hline 2 & 0.79 & $0.57,1.09$ & 0.82 & $0.59,1.14$ & 0.68 & $0.53,0.87$ & 0.72 & $0.55,0.92$ & 0.65 & $0.45,0.93$ & 0.66 & $0.45,0.95$ \\
\hline 3 & 0.79 & $0.58,1.09$ & 0.88 & $0.63,1.21$ & 0.67 & $0.53,0.86$ & 0.73 & $0.57,0.94$ & 0.64 & $0.45,0.92$ & 0.65 & $0.45,0.93$ \\
\hline 4 & 0.92 & $0.66,1.29$ & 1.03 & $0.73,1.46$ & 0.81 & $0.63,1.05$ & 0.88 & $0.68,1.16$ & 0.81 & $0.56,1.17$ & 0.79 & $0.54,1.16$ \\
\hline Trend† & 0.98 & $0.87,1.09$ & 1.02 & $0.91,1.14$ & 0.94 & $0.86,1.02$ & 0.96 & $0.88,1.05$ & 0.93 & $0.82,1.06$ & 0.93 & $0.82,1.06$ \\
\hline \multicolumn{13}{|l|}{ RFV(SAIN,LIM) } \\
\hline 1 & Ref & & Ref & & Ref & & Ref & & Ref & & Ref & \\
\hline 2 & 0.93 & $0.68,1.26$ & 0.99 & $0.72,1.35$ & 0.78 & $0.61,0.99$ & 0.83 & $0.65,1.06$ & 0.74 & $0.52,1.05$ & 0.76 & $0.53,1.08$ \\
\hline 3 & 0.93 & $0.67,1.28$ & 1.03 & $0.74,1.43$ & 0.76 & $0.59,0.99$ & 0.84 & $0.64,1.09$ & 0.78 & $0.54,1.12$ & 0.79 & $0.55,1.15$ \\
\hline 4 & 0.81 & $0.57,1.14$ & 0.91 & $0.64,1.30$ & 0.79 & $0.61,1.03$ & 0.87 & $0.66,1.13$ & 0.76 & $0.52,1.10$ & 0.75 & $0.51,1.10$ \\
\hline Trend $\dagger$ & 0.94 & $0.84,1.05$ & 0.98 & $0.87,1.09$ & 0.93 & $0.86,1.02$ & 0.96 & $0.88,1.05$ & 0.93 & $0.82,1.05$ & 0.92 & $0.81,1.05$ \\
\hline
\end{tabular}

FVS, food variety score (total food variety); Ref, reference; RFV, recommended food score (healthier food variety); Ofcom, UK Ofcom nutrient profiling model(38); SAIN,LIM, score for the nutritional adequacy of individual foods, score for disqualifying nutrients ${ }^{(26)}$.

* Model 1 adjusted for age, sex, ethnicity and energy intake; Model 2 further adjusted for marital status, employment grade, smoking status, physical activity level, alcohol intake, BMI categories and prevalence of longstanding illness. Models including the RFV were further adjusted for variety of less healthy foods.

† Linear trend was assessed using quartiles as continuous variable.

obese or overweight. These associations were weak but significant (except for RFV(SAIN,LIM)) and had not previously observed in Swedish and North-American women ${ }^{(13,14)}$, may be explained by socio-demographic characteristics of Whitehall II participants. In the UK, the prevalence of overweight or obesity is higher in men and in men with lowest income households, i.e. closer to the profile of participants with higher $\mathrm{FVS}^{(45)}$. In line with observations made in the $\mathrm{USA}^{(13)}$, age was positively associated with RFV scores, which would have explained the association between RFV scores and the prevalence of overweight and obesity.

A strength of the present study was the use of the Whitehall II cohort, in which participants have well-characterised health status and precisely determined socio-economic characteristics through repeated questionnaires and clinical examinations $^{(29)}$. Dietary intakes have been reported in a validated $\mathrm{FFQ}^{(31)}$, and dietary patterns identified either with cluster analysis or the Alternative Healthy Eating Index have been associated with the prospective risk of CHD, diabetes and mortality outcomes ${ }^{(4,46)}$. However, the Whitehall II sample size was smaller compared with previous examinations assessing health effects of recommended and non-recommended food variety ${ }^{(14,16)}$, resulting in a lower statistical power and wider CI. The exclusion of energy misreporters and individuals with reported prevalent longstanding illness further reduced the sample size, not allowing for robust conclusions despite the strength of the suggested associations.

A limitation of the present study was in the definition of the variety scores since they were very dependent on the FFQ tool itself. The Whitehall II FFQ put more emphasis on fruit and vegetables (thirty-four items) compared with meat and fish products (16), dairy products (13) or snack foods (12). Hereby, participants with higher FVS or RFV scores were mechanically more likely to have a varied and increased intake of fruit and vegetables. Nevertheless, post hoc analyses adjusted for fruit and vegetable intake did not alter the conclusions. The use of alternative dietary assessment methods with no pre-defined list of food items such as dietary records or $24 \mathrm{~h}$ recalls could help in overcoming such limitation. Latest national dietary surveys in the UK, USA and France used such dietary assessment methods ${ }^{(47-49)}$; however, these rarely include follow-up for incident chronic disease and/or mortality. In addition, all variety scores had a minimum of zero. These very low scores could be explained by either a very high dietary variety (i.e. more foods consumed less than once a week) or by underreporting. Sensitivity analyses excluding $1 \%$ of participants at the extremes of the variety score distributions did not alter the conclusions (data not shown), and Cox models excluding energy misreporters did not alter the conclusions from this report (post hoc analysis).

The stronger effects observed with the RFV scores compared with the NRFV scores, in particular, the cancer and all-cause mortality risk reduction observed with the middle quartiles of RFV(Ofcom), supported the rationale to promote higher variety of healthier foods and the move of Dietary Guidelines for Americans from the 'Eat a variety of food message' in $1995^{(50)}$ to the 'Eat a variety of vegetables' and 'Choose a variety of protein foods' messages in $2010^{(20)}$. As recently illustrated, individuals tend to focus more on less healthy foods when thinking of healthy diets ${ }^{(51)}$. The present results, 
which would need confirmation in larger data sets and using alternative nutrient profile models, therefore, suggest that more focus should be put on promoting healthier foods and total food variety.

In the present study and unlike previous observations, the significant protective associations of the RFV(Ofcom) score were observed in the middle quartiles, suggesting that intermediate variety of healthier foods may be more favourable than higher variety of such foods. In previous studies, the 'Recommended' foods were defined on an a priori basis using food-based dietary guidelines ${ }^{(14,16,52)}$, i.e. essentially linked to the identification of healthier dietary patterns rather than foods per se, which may have led to the stronger and linear protective effects. As an example, in the recent study by Larsson et $a l .{ }^{(52)}$, all fruit and vegetables and all fish products, but no meat or poultry products often associated with Western style dietary patterns, were included in the recommended food score. In addition, both the UK Ofcom and SAIN,LIM models were virtually across-the-board, i.e. they scored almost all foods using a similar algorithm. Such approach, although allowing to better align classification of foods with existing dietary guidelines, may not be the most appropriate to identify healthier dietary patterns ${ }^{(53)}$. Conducting similar analyses using category-specific models would allow assessing whether the present results could be explained by the choice of nutrient profile models.

Previous results regarding the association between increased variety of non-recommended foods and prospective health outcomes have not been consistent. No association has been found with all-cause mortality risk in a cohort of Swedish women $^{(14)}$; however, a positive association was observed with the risk of stroke in the same population ${ }^{(52)}$. A positive association with all-cause mortality risk was observed in Swedish men ${ }^{(16)}$. In addition, dietary variety of sweets, snacks, condiments, carbohydrates and entrées was associated with increased body fatness in a small US population ${ }^{(54)}$. No robust associations could be identified in the present study.

The use of nutrient profiling to identify the recommended (or healthier) and non-recommended (or less healthy/ unhealthy) foods was another strength of the present analysis since no previous assumption was made on the healthiness of particular foods. The stronger associations observed with the UK Ofcom nutrient profile model indicated that it may be a more adequate model to identify dietary patterns predictive of improved health status, compared with the SAIN,LIM. This result may be explained by the fact that the SAIN,LIM model was more restrictive when selecting healthier foods. As opposed to the RFV(Ofcom), foods such as pears, grapes, wholemeal bread, brown rice, boiled potatoes or vegetable soups were not included in the RFV(SAIN,LIM). In contrast, full-fat milk products were considered healthier by the SAIN, LIM and not by the UK Ofcom model. However, Darmon et $a l{ }^{(26)}$ have indicated that the SAIN,LIM did identify 'most unrefined starches and grains' as healthier in a French database. Differences in food composition database may explain these diverging classifications of foods, as well as the fact the Whitehall II FFQ items were calculated as weighted average of several individual foods, i.e. not reflecting the true nutrient content of specific foods. In addition, the SAIN,LIM was developed and validated using French data; an adaptation of criteria and target values may be needed when implementing the model on foreign data. The inclusion in the UK Ofcom algorithm of fruit, vegetable and nut content as a positive nutritional component could have explained the stronger associations; however, analyses adjusted for fruit, vegetable and nut intake did not alter the conclusions.

To the best of our knowledge, only one study has linked a nutrient profile model, the US Overall Nutrition Quality Index (ONQI), to prospective risk of chronic disease and mortality ${ }^{(55)}$. A diet index based on the ONQI was associated with modest reduced risk of total chronic disease, CVD, diabetes and total mortality in the US Nurses' Health study and Health Professionals Follow-up Study datasets. Unlike the RFV scores, the ONQI diet index did not account for diet variety. Cross-validation of the present results with the ONQI model and in the two US data sets would strengthen the nutrient profiling rationale.

The results from the present analysis strongly support the inclusion of messages recommending increased overall diet variety and variety from healthier foods in public health recommendations. In this respect, nutrient profiling could become the most adequate tool to help identify healthier foods; however, more research is needed to assess nutrient profile models and their ability to predict prospective health in various populations. The consistency with previous results with regard to the association between food variety and nutritional adequacy would support the generalisability of the present findings. The use of alternative datasets, and more particularly alternative dietary assessment tools, should therefore confirm the beneficiary health effects of total food variety and variety of healthier food options.

\section{Supplementary material}

To view supplementary material for this article, please visit http://dx.doi.org/10.1017/S000711451500094X

\section{Acknowledgements}

The authors thank all the participating civil service departments and their welfare, personnel and establishment officers; the Occupational Health and Safety Agency; the Council of Civil Service Unions; all participating civil servants in the Whitehall II study; and all the members of the Whitehall II study team.

The present study was supported by the British Heart Foundation (FS/08/043/25495) and the French Agence Nationale de la Recherche (ANR-11-ALID-0002). The Whitehall II study was supported by grants from the Medical Research Council; Economic and Social Research Council; British Heart Foundation; Health and Safety Executive; Department of Health; National Heart Lung and Blood Institute (HL36310), US, NIH; National Institute on Aging (AG13196), US, NIH; Agency for Health Care Policy Research (HS06516); and the John D. and Catherine T. MacArthur Foundation Research Networks on Successful Midlife Development and 
Socioeconomic Status and Health. The funders had no role in the study design and analysis, decision to publish, or in the preparation of the manuscript.

All authors declare no conflict of interest.

The authors' contributions are as follows: G. Masset conceived the analysis, analysed the data and drafted the first manuscript; P. S., M. R., E. J. B. and G. Mishra provided the essential materials and assisted with the preparation of the manuscript. All authors contributed in drafting the final manuscript.

\section{References}

1. Kant AK (2004) Dietary patterns and health outcomes. J Am Diet Assoc 104, 615-635.

2. Hoffmann K, Schulze MB, Schienkiewitz A, et al. (2004) Application of a new statistical method to derive dietary patterns in nutritional epidemiology. Am J Epidemiol 159, 935-944.

3. Kant AK, Graubard BI \& Schatzkin A (2004) Dietary patterns predict mortality in a national cohort: the National Health Interview Surveys, 1987 and 1992. J Nutr 134, 1793-1799.

4. Brunner EJ, Mosdol A, Witte DR, et al. (2008) Dietary patterns and 15-y risks of major coronary events, diabetes, and mortality. Am J Clin Nutr 87, 1414-1421.

5. Drewnowski A, Henderson SA, Shore AB, et al. (1996) Diet quality and dietary diversity in France: implications for the French paradox. I Am Diet Assoc 96, 663-669.

6. Hatloy A, Torheim LE \& Oshaug A (1998) Food variety - a good indicator of nutritional adequacy of the diet? A case study from an urban area in Mali, West Africa. Eur J Clin Nutr 52, 891-898.

7. Savy M, Martin-Prevel Y, Sawadogo P, et al. (2005) Use of variety/diversity scores for diet quality measurement: relation with nutritional status of women in a rural area in Burkina Faso. Eur J Clin Nutr 59, 703-716.

8. Oldewage-Theron WH \& Kruger R (2008) Food variety and dietary diversity as indicators of the dietary adequacy and health status of an elderly population in Sharpeville, South Africa. J Nutr Elder 27, 101-133.

9. Steyn N, Nel J, Nantel G, et al. (2007) Food variety and dietary diversity scores in children: are they good indicators of dietary adequacy? Public Health Nutr 9, 644-650.

10. Fernandez E, Negri E, La Vecchia C, et al. (2000) Diet diversity and colorectal cancer. Prev Med 31, 11-14.

11. Fernandez E, D'Avanzo B, Negri E, et al. (1996) Diet diversity and the risk of colorectal cancer in northern Italy. Cancer Epidemiol Biomarkers Prev 5, 433-436.

12. Wahlqvist ML, Lo CS \& Myers KA (1989) Food variety is associated with less macrovascular disease in those with type II diabetes and their healthy controls. J Am Coll Nutr $\mathbf{8}, 515-523$.

13. Kant AK, Schatzkin A, Graubard BI, et al. (2000) A prospective study of diet quality and mortality in women. Jama $\mathbf{2 8 3}$, 2109-2115.

14. Michels KB \& Wolk A (2002) A prospective study of variety of healthy foods and mortality in women. Int J Epidemiol 31, 847-854.

15. McCullough ML, Feskanich D, Stampfer MJ, et al. (2002) Diet quality and major chronic disease risk in men and women: moving toward improved dietary guidance. Am J Clin Nutr 76, 1261-1271.
16. Kaluza J, Hakansson N, Brzozowska A, et al. (2009) Diet quality and mortality: a population-based prospective study of men. Eur J Clin Nutr 63, 451-457.

17. US Department of Agriculture (2012) ChooseMyPlate. gov. http://www.choosemyplate.gov/about.html (accessed March 2015).

18. National Health Service (2011) The eatwell plate http:// www.nhs.uk/Livewell/Goodfood/Pages/eatwell-plate.aspx (accessed November 2013).

19. Ministère du travail de l'emploi et de la santé (French Department of Work and Health) (2011) Programme national nutrition santé - 2011-2015 (National Health and Nutrition Program 2011-2015). Paris: French Department of Work and Health. http://www.sante.gouv.fr/IMG/ pdf/PNNS_2011-2015.pdf (accessed March 2014).

20. US Department of Agriculture \& US Department of Health and Human Services (2010) Dietary Guidelines for Americans 2010, 7th ed. Washington DC: US Government Printing Office.

21. World Health Organization (2011) Nutrient Profiling Report of a WHO/IASO Technical Meeting - London, United Kingdom, 4-6 October 2010. Geneva: WHO.

22. Office of Communications (2007) Television Advertising of Food and Drink Products to Children - Final statement. London: Ofcom.

23. Broadcasting Authority of Ireland (2013) Revised General and Children's Commercial Communications Codes - June 2013. Dublin: Broadcasting Authority of Ireland. http://www.bai.ie/ ?page_id=3364 (accessed October 2013).

24. Food Standards Australia New Zealand (2013) Standard 1.2.7 - Nutrition, Health and Related Claims. Australian Federal Register of Legislative Instruments F2014C01191. http://www.comlaw.gov.au/Details/F2013L00054 (accessed October 2013).

25. Agence française de sécurité sanitaire des aliments (2008) Définition de profils nutritionnels pour l'accès aux allégations nutritionnelles et de santé: propositions et arguments (The Setting of Nutrient Profiles for Access to Nutrition and Health: Proposals and Arguments). Paris: Agence française de sécurité sanitaire des produits de santé.

26. Darmon N, Vieux F, Maillot M, et al. (2009) Nutrient profiles discriminate between foods according to their contribution to nutritionally adequate diets: a validation study using linear programming and the SAIN,LIM system. Am J Clin Nutr 89, 1227-1236.

27. The European Parliament and the Council of the European Union (2006) Regulation (EC) no. 1924/2006 of the European Parliament and the Council of the European Union of 20 December 2006 on nutrition and health claims made on food. Off J Eur Union L404, 9-25.

28. Rayner M, Scarborough P \& Kaur A (2013) Nutrient profiling and the regulation of marketing to children. Possibilities and pitfalls. Appetite 62, 232-235.

29. Marmot M \& Brunner E (2005) Cohort Profile: the Whitehall II study. Int J Epidemiol 34, 251-256.

30. Willett WC, Sampson L, Stampfer MJ, et al. (1985) Reproducibility and validity of a semiquantitative food frequency questionnaire. Am J Epidemiol 122, 51-65.

31. Brunner E, Stallone D, Juneja M, et al. (2001) Dietary assessment in Whitehall II: comparison of $7 \mathrm{~d}$ diet diary and food-frequency questionnaire and validity against biomarkers. Br J Nutr 86, 405-414.

32. Brunner EJ, Marmot MG, White IR, et al. (1993) Gender and employment grade differences in blood cholesterol, apolipoproteins and haemostatic factors in the Whitehall II study. Atherosclerosis 102, 195-207. 
33. Whitworth JA (2003) 2003 World Health Organization (WHO)/International Society of Hypertension (ISH) statement on management of hypertension. J Hypertens 21, $1983-1992$.

34. French Medicine Agency (Afssaps) (2005) Prise en charge thérapeutique du patient dyslipidémique (Getting Patient Therapeutic Dyslipidemic), vol. 33, Saint-Denis, FR: Agence française de sécurité sanitaire des produits de santé

35. Alberti KG \& Zimmet PZ (1998) Definition, diagnosis and classification of diabetes mellitus and its complications. Part 1: diagnosis and classification of diabetes mellitus provisional report of a WHO consultation. Diabet Med 15, 539-553.

36. Rose $G$ (1982) Incubation period of coronary heart disease. Br Med J (Clin Res Ed) 284, 1600-1601.

37. World Health Organization (1999) Definition, Diagnosis and Classification of Diabetes Mellitus and its Complications. Report of a WHO Consultation, Part 1: Diagnosis and Classification of Diabetes Mellitus. Geneva: World Health Organization.

38. Rayner M, Scarborough P \& Lobstein T (2009) The UK Ofcom Nutrient Profiling Model. Oxford: British Heart Foundation Health Promotion Research Group.

39. Madden JP, Goodman SJ \& Guthrie HA (1976) Validity of the 24-hr. recall. Analysis of data obtained from elderly subjects. J Am Diet Assoc 68, 143-147.

40. Department of Health (1991) Dietary reference values for food energy and nutrients for the United Kingdom. Report of the Panel on Dietary Reference Values of the Committee on Medical Aspects of Food Policy. Rep Health Soc Subj 41, 1-210.

41. Vieux F, Soler L-G, Touazi D, et al. (2013) High nutritional quality is not associated with low greenhouse gas emissions in self-selected diets of French adults. Am J Clin Nutr 97, 569-583.

42. Cox DR (1972) Regression models and life-tables. $J$ R Stat Soc B 34, 187-220.

43. Schoenfeld D (1982) Partial residuals for the proportional hazards regression model. Biometrika 69, 239-241.

44. Black AE (2000) The sensitivity and specificity of the Goldberg cut-off for EI:BMR for identifying diet reports of poor validity. Eur J Clin Nutr 54, 395-404.

45. Sutton R (2012) Adult anthropometric measures, overweight and obesity. In Health Survey for England - 2011, Health,
Social Care and Lifestyles, pp. 325-362 [R Craig and J Mindell, editors]. Leeds: Health and Social Care Information Centre.

46. Akbaraly TN, Ferrie JE, Berr C, et al. (2011) Alternative Healthy Eating Index and mortality over 18 y of follow-up: results from the Whitehall II cohort. Am J Clin Nutr 94, $247-253$

47. Department of Health \& Food Standards Agency (2011) National Diet and Nutrition Survey. In Headline Results from Years 1 and 2 (Combined) of the Rolling Programme (2008/2009-2009/2010), [B Bates, A Lennox and C Bates, et al., editorss]. London: Department of Health.

48. Centers for Disease Control and Prevention \& National Center for Health Statistics (2012) National Health and Nutrition Examination Survey. Hyattsville, MD: US Department of Health and Human Services.

49. Unité de Surveillance et d'Épidémiologie Nutritionnelle (2007) Étude nationale nutrition santé - ENNS, 2006 (National Nutritional Health Study - ENNS 2006). SaintMaurice, FR: Institut de veille sanitaire.

50. US Department of Agriculture \& US Department of Health and Human Services (1995) Nutrition and Your Health: Dietary Guidelines for Americans. 4th ed. Home and Garden Bulletin no. 232. http://www.health.gov/dietaryguidelines/dga95/ (accessed March 2015).

51. Macdiarmid JI, Loe J, Kyle J, et al. (2013) It was an education in portion size. Experience of eating a healthy diet and barriers to long term dietary change. Appetite 71, 411-419.

52. Larsson SC, Akesson A \& Wolk A (2014) Overall diet quality and risk of stroke: a prospective cohort study in women. Atherosclerosis 233, 27-29.

53. Scarborough P, Arambepola C, Kaur A, et al. (2010) Should nutrient profile models be category specific or acrossthe-board? A comparison of the two systems using diets of British adults. Eur J Clin Nutr 64, 553-560.

54. McCrory M a, Fuss PJ, McCallum JE, et al. (1999) Dietary variety within food groups: association with energy intake and body fatness in men and women. Am J Clin Nutr 69, 440-447.

55. Chiuve SE, Sampson L \& Willett WC (2011) The association between a nutritional quality index and risk of chronic disease. Am J Prev Med 40, 505-513. 